\title{
Cardiac Diseases and Obesity
}

\author{
Sanjeev Kathuria ${ }^{1}$, Abhimanyu Uppal ${ }^{2}$, Vimal Mehta ${ }^{3}$, Anunyay Gupta ${ }^{4}$
}

\begin{abstract}
Obesity is a raging epidemic with a significant impact on cardiovascular health profile. It harbingers the development of both structural [coronary artery disease (CAD), heart failure (HF)] and electrical (atrial fibrillation) cardiac disorders. On a background of low-grade chronic inflammation, the changes in body composition, hemodynamic alterations, and myocardial fat deposition accelerate the associated cardiovascular morbidity. Quite counterintuitively, obese patients having CAD or HF fare better than their normal-weight counterparts; a phenomenon described as the "obesity paradox". An increase in lean mass (LM) and consequent improvement in cardiorespiratory fitness (CRF), partly explains this phenomenon. In the following review, we aim to decipher the links between obesity and cardiovascular diseases (CVDs) along with the evolving concept of "adiposopathy" and current evidence shedding light on the intriguing "obesity paradox". The significance of estimating and improving CRF is also discussed along with current recommendations for managing obesity.

Keywords: Cardiorespiratory fitness, Epicardial fat, Metabolically healthy obese, Obesity, Obesity paradox.

Journal of Postgraduate Medicine, Education and Research (2021): 10.5005/jp-journals-10028-1423
\end{abstract}

\section{INTRODUCTION}

Being obese is a challenging health concern that affects people from varying demographics with different sociocultural backgrounds. Data from the World Health Organization (WHO) underscores the ever-expanding prevalence of this non-communicable disease. Thirty-nine percent of adults across the world are overweight and $13 \%$ are obese. ${ }^{1}$

Obesity as defined by WHO is an increase in fat mass (FM) which impairs health. Body mass index $(\mathrm{BMI}) \geq 30 \mathrm{~kg} / \mathrm{m}^{2}$ is the most accepted definition of obesity. It is further classified into:

- Class I: BMI between 30.0 and $34.9 \mathrm{~kg} / \mathrm{m}^{2}$.

- Class II: BMI between 35.0 and $39.9 \mathrm{~kg} / \mathrm{m}^{2}$.

- Class III: BMI exceeding $40.0 \mathrm{~kg} / \mathrm{m}^{2}$.

Overweight is considered when BMI is $\geq 25 \mathrm{~kg} / \mathrm{m}^{2}$. World Health Organization has suggested modified BMI cutoffs in Asian subjects because they have proportionately more visceral fat for a given BMI. This makes them particularly vulnerable to the adverse effects of obesity. Thus, the modified cutoffs are BMI $\geq 23 \mathrm{~kg} / \mathrm{m}^{2}$ for overweight and $\geq 25 \mathrm{~kg} / \mathrm{m}^{2}$ for obesity. ${ }^{2}$

Cardiac conditions like coronary artery disease (CAD), heart failure (HF), and rhythm disturbances have been linked to obesity. ${ }^{1}$ Obesity has also been shown to independently influence cardiac outcomes. But this linear relationship does not hold in the setting of an already established cardiac disease. This means that before the onset of a cardiovascular disease (CVD), reducing bodyweight can serve as a primary prevention strategy. But once a cardiac disease has already set-in, then obesity has a paradoxical protective effect for cardiovascular outcomes, a phenomenon termed the "obesity paradox". ${ }^{3}$ This review will highlight the occurrence of this phenomenon in various conditions like HF, coronary atherosclerosis, arrhythmias, etc. ${ }^{4}$

Furthermore, we will discuss the significance of compartmentalizing obesity into $F M$, lean mass (LM), and fat-free mass (FFM) to improve CVD risk stratification. Current views on the interesting entity called "metabolically healthy obese" and the
${ }^{1-4}$ Department of Cardiology, GB Pant Hospital, New Delhi, India

Corresponding Author: Sanjeev Kathuria, Department of Cardiology, GB Pant Hospital, New Delhi, India, Phone: +91 8851958380, e-mail: sanjeevkath@hotmail.com

How to cite this article: Kathuria S, Uppal A, Mehta V, et al. Cardiac Diseases and Obesity. J Postgrad Med Edu Res 2021;55(1):12-20.

Source of support: Nil

Conflict of interest: None

emerging role of epicardial fat affecting CVD will be highlighted. The concept of cardiorespiratory fitness (CRF) as a novel yardstick to define therapeutic targets will be reviewed with a brief discussion about the currently accepted benefits of lifestyle changes, drug therapy, and surgical options in the management of obesity.

\section{Epidemiology}

As per the latest epidemiological studies, the overweight adult population is about 1.9 billion while obesity affects almost 6.50 billion adults. Nearly 2.8 million lives are lost annually as a consequence of obesity-related illnesses. ${ }^{5}$ Consequent to the adoption of western dietary habits like the over-consumption of refined carbohydrates and saturated fats coupled with a sedentary lifestyle, the financially challenged healthcare systems of underdeveloped nations are now suffering the toughest impact of obesity. Presently, almost 13.5 crore Indians suffer from obesity. The growing menace of obesity in India has spread to involve $11.8-31.3 \%$ of the population; among them, abdominal obesity shows prevalence between $16.9 \%$ and $36.3 \%{ }^{6}$

Obesity in south Asians shows certain peculiar features. Compared to western populations, their body fat is comprised of proportionately more visceral fat and there is more prevalence of insulin resistance. The differing body composition compels faster pancreatic beta-cell destruction and early onset diabetes mellitus (DM), thus highlighting the importance of body composition rather than anthropometric indices alone in risk stratifying these patients. ${ }^{7}$

\footnotetext{
(c) The Author(s). 2021 Open Access This article is distributed under the terms of the Creative Commons Attribution 4.0 International License (https:// creativecommons.org/licenses/by-nc/4.0/), which permits unrestricted use, distribution, and non-commercial reproduction in any medium, provided you give appropriate credit to the original author(s) and the source, provide a link to the Creative Commons license, and indicate if changes were made. The Creative Commons Public Domain Dedication waiver (http://creativecommons.org/publicdomain/zero/1.0/) applies to the data made available in this article, unless otherwise stated.
} 


\section{Fit-fat Patient: Metabolically Healthy Obesity}

The concept of metabolically healthy obese (MHO) stems from the fact that not all overweight or obese patients have increased CVD risk. Most of the association between adiposity indices and CVD is explained by the altered levels of intermediate risk factors and not by the bodyweight per se. Such intermediaries include a constellation of metabolic abnormalities, including insulin resistance leading to type $2 \mathrm{DM}$, atherogenic dyslipidemia, elevated blood pressure (BP), subtle chronic inflammation, and a prothrombotic profile; collectively termed the metabolic syndrome (MS). ${ }^{8}$ Metabolic syndrome is generally characterized by the accumulation of excess fat in visceral depots. For any given level of total body fat, individuals showing a lack of excess abdominal visceral adipose tissue have a lower CVD risk profile than individuals harboring its excess. The concept of MHO has introduced a change in approach to obesity from that of a "one-size-fits-all" approach to an individualistic approach whereby not only total body fat content but also its regional distribution has assumed paramount significance.

\section{BMI and CVD Flummox: Search for Novel Measurements}

The inherent limitation of BMI is that it gives no information on fat distribution. In an obese phenotype, the clinician has two choices: to reduce CVD risk by targeting conventional risk factors like low-density lipoprotein cholesterol (LDL-C), BP, and uncontrolled hyperglycemia with pharmacological agents or to target weight loss. Randomized trials have established the clinical benefits of targeting the BP, LDL-C and achieving appropriate glycemic control, but no weight-loss drug has clearly shown any benefit in cardiovascular events and mortality, except for some new diabetes drugs. " "Look AHEAD" trial (studying diet and losing weight in obese diabetic subjects) showed that intensive weight-loss interventions did not result in any reduction in CVD events despite beneficial effects on some CVD risk factors and quality of life..$^{10}$

This suggests that instead of reducing total bodyweight, the target should be to reduce the fat that "troubles the most", i.e., the visceral fat. To estimate this entity newer physical assessments like abdominal circumference and waist/hip ratio (WHR) are useful. In males, an abdominal girth $\geq 102 \mathrm{~cm}$ defines central obesity and predicts future cardiac events (for females the corresponding cutoff is $\geq 88 \mathrm{~cm}$ ). A WHR $\geq 0.9$ in males (and $\geq 0.85$ in females) is another criterion. ${ }^{9}$ For Asian-Indian patients, these cutoffs are revised as:

- A waist circumference of $\geq 85 \mathrm{~cm}$ in males ( $\geq 80 \mathrm{~cm}$ for females). - Waist/hip ratio as $\geq 0.88$ for males ( $\geq 0.81$ for females). ${ }^{2}$

\section{Compartmentalizing Obesity}

The regional distribution of adipose tissue, as discussed earlier, is more significant than the total body adipose content. The rise in BMI may be a consequence of an increase in subcutaneous fat, visceral fat, or both, with a concomitant rise or fall in LM. Among these, visceral fat (estimated from waist circumference) is considered the prime culprit. It incites the synthesis of adipokines and various cytokines. These biological compounds with their cardiac-depressant and pro-atherosclerotic properties become the chief predictors of future CV events. ${ }^{11}$ On the contrary, excess accumulation of fat in the lower body (hips and thighs) may actually reduce the chances of developing CVD or diabetes. ${ }^{9}$

Increased BMI is almost always mirrored by a rise in FFM. Conversely, if FFM decreases in the face of an increased FM, then it is known as the sarcopenic variant of obesity. By compartmentalizing the bodyweight, we can also distinguish the beneficial rise in BMI in an athlete from the sarcopenic and nonsarcopenic variants of obesity (Fig. 1). ${ }^{12}$

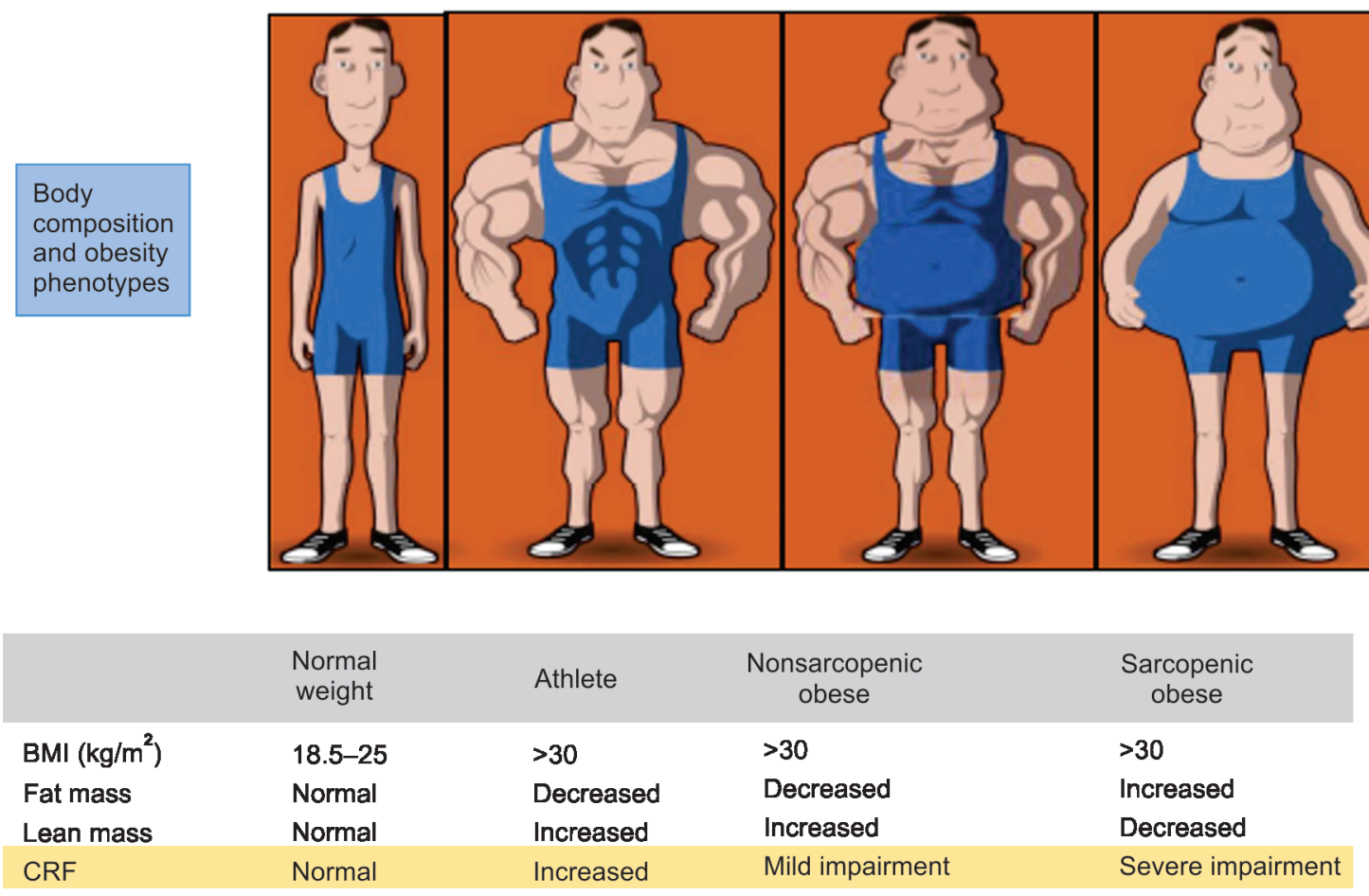

Fig. 1: Various phenotypes of increased BMI according to proportion of fat and lean mass. BMI, body mass index; CRF, cardiorespiratory fitness 


\section{Pathogenesis: The Concept of Adiposopathy}

Multiple factors converge to cause obesity including:

- Genetic predisposition, sociocultural, and environmental situations.

- Behavioral and physiological components.

- Epigenetic risk factors.

Hereditary predisposition also arises from epigenetic mechanisms. Research has implicated approximately 140 chromosomal loci with this condition. ${ }^{13}$

Gut microbiota has also been incriminated in the predisposition to obesity. Bacterial lipopolysaccharide triggers an inflammatory cascade. This has effects on behavior control areas of the brain and also leads to derangement of adipose tissue functioning. The final result is weight gain with an enhanced risk of metabolic and cardiac diseases (Fig. 2A). ${ }^{13}$

Adiposopathy is the pathological alteration in the normal functioning of adipocytes that occurs as a consequence of energy intake exceeding energy expenditure and an inactive lifestyle. ${ }^{14}$ It is manifested by fat-cell hypertrophy, increased visceral, pericardial, perivascular, and peri-organ adiposity whose nutritional requirements are unmet by the existing vascular supply and resultant ischemia culminates in the release of inflammatory mediators.

\section{Why Specifically Visceral Fat Worsens CV Outcomes?}

Plausible explanations for this include:

- Portal vein serving as a conduit to deliver the free fatty acids (FFAs) from hypertrophied adipocytes (in the omentum) directly to hepatocytes. This promotes the excess hepatic triglyceride and glucose production.
- Visceral adipose tissue expanding through hypertrophy rather than hyperplasia generates rupture-prone fat cells that incite an inflammatory state.

- An increase in visceral fat may be a reflection of spill-over due to saturation of subcutaneous fat depots (which behaves as a protective "metabolic sink" in healthy individuals). ${ }^{9}$

Apart from fat tissues, two other systems regulate bodyweight: the appetite and satiety centers in the brain, and the endocrine system in the gastrointestinal tract. ${ }^{15}$ Peripheral nervous system regulates the heat production by controlling musculoskeletal activities. The autonomic (sympathetic) nervous system also regulates energy expenditure. ${ }^{15,16}$ Gastrointestinal endocrine system is involved in satiety and hunger signaling. This effect is mediated by hormones like leptin, insulin, glucagon-like peptide-1 (GLP-1), peptide YY (PYY), cholecystokinin (CCK), and ghrelin (Fig. 2B). Their signaling pathways converge to relay details regarding the energy equilibrium to the hypothalamus and other cerebral centers. These areas then modulate the urge to consume food by interacting with the reward centers of the brain. ${ }^{16}$ Perturbations of the fine balance between hunger, satiety, and energy expenditure knit the pathogenesis of obesity.

\section{Emerging Role of Epicardial Fat}

Epicardial fat occupies the potential space between the visceral pericardium and cardiac musculature. The most notable locations are the confluence sites between the ventricles and the atrioventricular grooves. There is no fascial barrier between this fat layer and the underlying muscles and hence share a common microcirculation. It has been suggested that tumor necrosis factor- $a$ (TNF- $a$ ) is secreted by adipocytes embracing the arteriolar origin sites. This cytokine causes inhibition of insulin-dependent engagement of capillaries and thus functions as a "vasocrine" signal. Myocardial blood supply can thus be altered by this epicardial fat. ${ }^{17}$
Process of inflammation in obesity

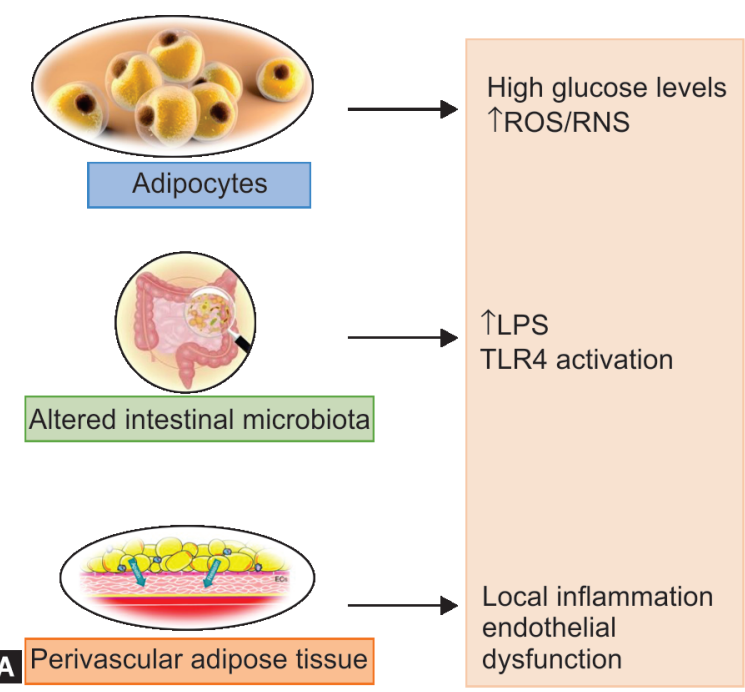

Relation of obesity and cardiovascular risk

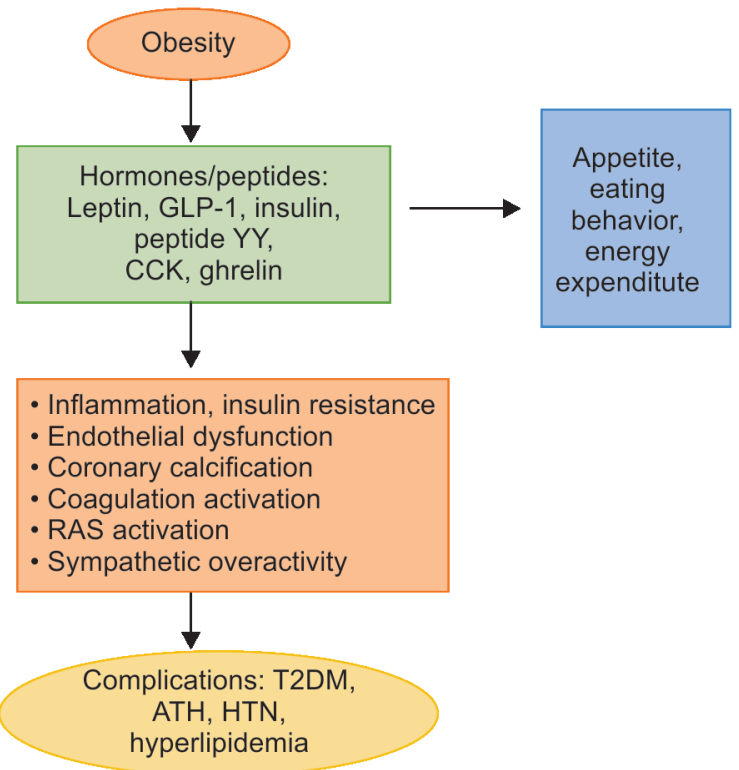

Figs $2 \mathrm{~A}$ and B: Pathogenic mechanisms in obesity and its impact on cardiovascular diseases. ROS, reactive oxygen species; RNS, reactive nitrogen species; LPS, lipopolysaccharide; TLR, toll-like receptor; CCK, cholecystokinin; GLP-1, glucagon-like peptide-1; PYY, peptide YY;T2DM, type 2 diabetes mellitus; ATH, atherosclerosis; HTN, hypertension 
Epicardial fat also has other well-defined physiological roles. It acts as an immunological "fence" to protect the cardiomyocytes and coronary arteries from inflammation-induced damage. Also, there is a mechanical "cushion" provided to the epicardial vessels because it provides space for positive remodeling to occur. This fat also serves as a nutritive depot by providing fatty acids to the heart during a high energy-demand state like exercise. ${ }^{18}$ Myocardial triglyceride content is strongly related to epicardial fat depots as shown by magnetic resonance and spectroscopy findings. ${ }^{19}$

The physiological properties assume a pathological nature when excess deposition of pericardial fat is not paralleled by a proportionate increase in blood supply. The ensuing ischemia triggers inflammation and sets the stage for CVD.

Data from various studies like Framingham and MESA studies have highlighted a direct association between the magnitude of epicardial fat and the presence and severity of coronary atherosclerosis. ${ }^{20,21}$ Infiltration of this ectopic fat into the interstitium can also alter the diastolic properties of the myocardium and affect the electrical impulse propagation (increasing the risk of AF). ${ }^{22}$

\section{How Obesity "Weighs Down" on Cardiovascular System?}

\section{Obesity and Atherosclerosis}

Several common factors underlie the pathology of obesity and atherosclerotic changes in the arteries. As with atherosclerosis, obesity is also incited against a background of systemic inflammation caused by lipid peroxidation (Fig. 3A). Other common features include a cytokine-induced insulin-resistance, endothelium damage, and a procoagulant milieu. ${ }^{23,24}$ Studies report that an obese profile, sustained for a minimum of 20 years, independently increases the risk of CAD. For every $10 \mathrm{~kg}$ increment in weight, CAD risk rises by $12 \% .{ }^{25}$ In young subjects, the risk of developing ST-elevation myocardial infarction (STEMI) also seems to be dependent on excess bodyweight. ${ }^{26}$ For cerebrovascular outcomes, per unit rise in BMI causes 4 and $6 \%$ increment in the risk for ischemic attacks and cerebral bleeds, respectively. ${ }^{27}$

\section{Obesity and Risk of Heart Failure}

Framingham Heart Study reported that per unit rise in BMI augments myocardial dysfunction risk by $5 \%$ for males (and $7 \%$ for females). ${ }^{28}$ More than one-third of patients with $\mathrm{HF}$ are affected by obesity. Also, in obese patients, there is almost a decade earlier onset of HF than normal-weight patients. ${ }^{29}$

Obesity-induced morphological and physiological alterations in the myocardium constitute "obesity cardiomyopathy" that ultimately causes HF (Fig. 3B). ${ }^{30}$ Dual mechanisms of renin-angiotensinaldosterone system (RAAS) activation and sympathetic overdrive act to increase myocardial fibrotic changes, endothelial injury, and increased thrombogenicity. ${ }^{31}$ Eplerenone acting as an inhibitor of RAAS was shown to benefit obese patients having $\mathrm{HF}$ with reduced ejection fraction in the EMPHASIS-HF trial. ${ }^{32}$ Renin-angiotensinaldosterone system activation and sympathetic drive increase blood volume and thus augment preload. These two systems also raise afterload by causing systemic hypertension. Remodeling process initiated by these changes instigates pathological impairment of both systolic and diastolic phases of the cardiac cycle leading to HF. Proinflammatory cytokines belonging to the interleukin and tumor necrosis factor family, and hormones leptin and adiponectin also promote this dysfunction. ${ }^{33}$

\section{Obesity and Cardiac Arrhythmias}

Hippocrates observed that "sudden death is more common in those who are naturally fat than in the lean". Consolidating this statement, various studies have linked obesity with rhythm disturbances, which can sometimes be life-threatening. ${ }^{34,35}$

Atrial fibrillation (AF) has a significant impact on the quality of life and mortality and poses a significant economic burden. Nearly one-third of arrhythmia-related admissions are attributable to AF. The chances of developing AF increase by $4 \%$ per unit rise in BMI. ${ }^{36}$ Obesity causes left atrial dilation and dysfunction. A 5 -mm increase in left atrial diameter increases the chances of paroxysmal AF by 1.39 times. ${ }^{36}$ Epicardial fat initiates fibrotic changes in atria through its vasocrine signaling. The adipocytes from this fat depot also infiltrate the underlying atrial muscles and further promote inflammation. These factors derail the organized electrical conduction in atrial tissue leading to disharmony between
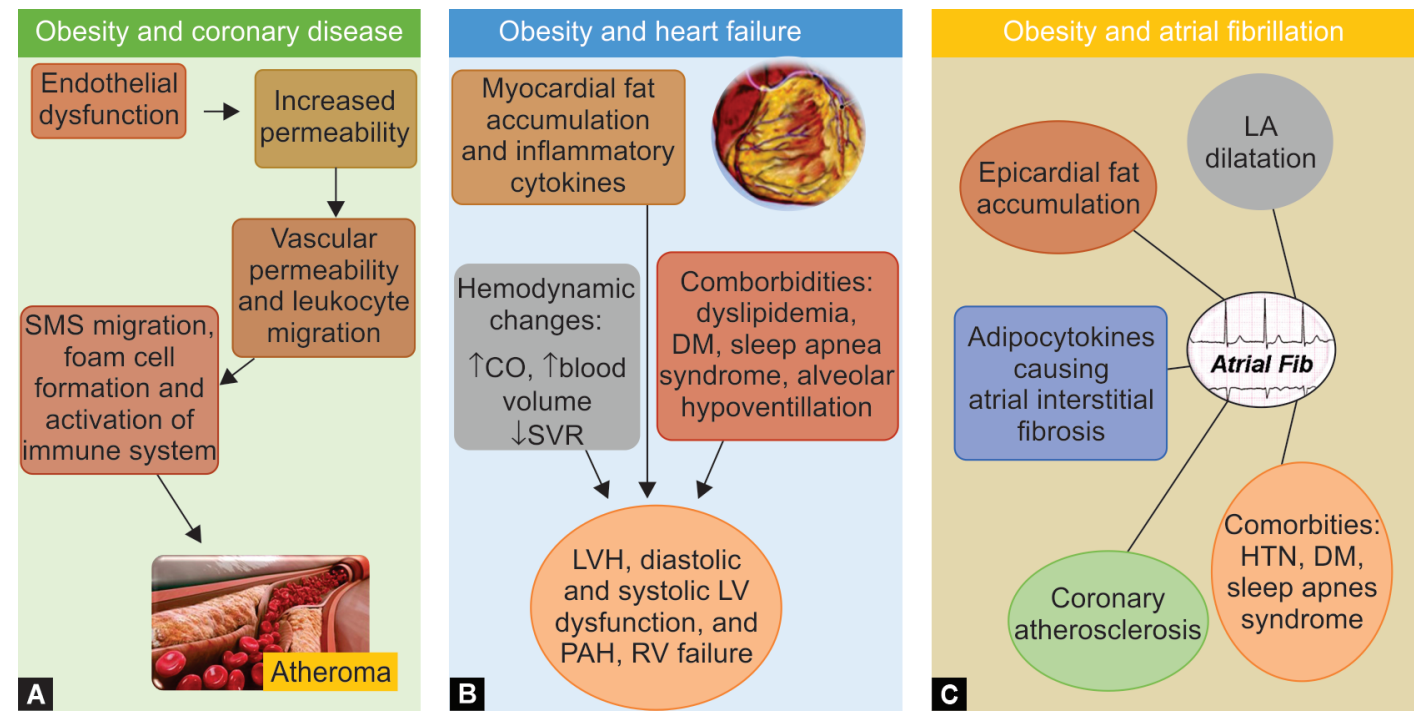

Figs 3 A to C: Detrimental impact of obesity on various cardiovascular entities: (A) Coronary artery disease; (B) Heart failure; (C) Atrial arrhythmias. SMC, smooth muscle cell; CO, cardiac output; SVR, systemic vascular resistance; DM, diabetes mellitus; LVH, left ventricular hypertrophy; LV, left ventricle; $\mathrm{PAH}$, pulmonary artery hypertension; $\mathrm{RV}$, right ventricle; $\mathrm{LA}$, left atrium; $H T N$, hypertension 
epicardial and sub-endocardial potentials and facilitate re-entry arrhythmias (Fig. 3C). Arrhythmogenicity is also promoted by leptin which increases myocyte depolarization time. Obesity leads to ECG changes like increased duration and height of $P$ waves, prolongation of PR interval, and terminal deflection of $P$ wave. ${ }^{37}$

Besides AF, ventricular tachyarrhythmias may also be a consequence of obesity. A remodeled ventricle with concomitant fibrosis leads to electrical disruption in impulse propagation. This is further augmented by the effects of epicardial fat as noted above. ${ }^{36}$ An electrical rearrangement occurs owing to alteration in potassium channel (voltage-gated) functioning and sympathetic overdrive. There is resultant QT and QTc (corrected QT interval) lengthening which promotes arrhythmogenesis. ${ }^{38}$

\section{Obesity Paradox}

Although obesity increases the risk of developing CVD, it is noteworthy that once a particular disease phenotype is established then the excess weight actually improves the prognosis. This is termed the obesity paradox which has been noted in a wide range of obesity-related cardiac conditions. ${ }^{36,39}$

\section{Obesity Paradox in Heart Failure}

Clinical outcomes in HF are improved by associated obesity. Allcause and cardiovascular deaths were found to be $16 \%$ and $19 \%$ lower in overweight patients, respectively, compared with normalweight subjects. This paradoxical protection is further magnified in obese patients where mortality difference is $33 \%$ for all-cause and $40 \%$ for cardiovascular causes. ${ }^{40}$ Another meta-analysis has reported that in comparison to non-obese HF patients the risk of all-cause mortality is reduced by a factor of 0.78 and cardiac-specific mortality by a factor of $0.80 .^{41}$ This paradox is especially noted in patients belonging to class / obesity. ${ }^{42}$

\section{Obesity Paradox and Coronary Revascularization}

Pooled data from BARI, Scottish Coronary Revascularization, and APPROACH registries derived for patients undergoing coronary angioplasty have suggested a reciprocal correlation between BMI and the percutaneous coronary intervention (PCI)-related shortterm complications. ${ }^{36}$

\section{Obesity Paradox and Chronic Inflammation}

As already discussed, chronic inflammation is the hallmark of obesity. The phenomenon of obesity paradox peculiarly occurs in the setting of milder grades of systemic inflammation [defined by high sensitivity (hs)-CRP $<3 \mathrm{mg} / \mathrm{L}]$ (Fig. 4A). This is reflected by the fact that an obese CAD patient having high FM with low hs-CRP has a better prognosis. Thus, the brunt of excess body fat is somewhat offset by the concurrent mild systemic inflammation. ${ }^{43}$

\section{Concept of Cardiorespiratory Fitness: An Emerging Tool}

The capacity of respiratory and circulatory systems to meet the oxygen demand of the musculoskeletal system during sustained exercise is defined as CRF. It is best measured by peak oxygen consumption, i.e., $\mathrm{VO}_{2}$ max. Higher $\mathrm{CRF}$ seen in obesity occurs by virtue of an increase in LM that parallels an increase in FM (Fig. 4B). The obesity paradox is observed only in the setting of low CRF, i.e., when the linear relation between LM and FM is not followed. This paradoxical relationship is not seen in patients having $\mathrm{VO}_{2}$ $\max >14 \mathrm{~mL} / \mathrm{kg} /$ minute or more than four-metabolic equivalents of task (METS). ${ }^{12}$ In obese individuals, peak $\mathrm{VO}_{2}$ when indexed to weight ( $\mathrm{mL} / \mathrm{kg} / \mathrm{minute}$ ) underestimates CRF. ${ }^{44}$ This shortcoming is addressed by adjusting peak $\mathrm{VO}_{2}$ to $\mathrm{FFM}$. A threshold of $19 \mathrm{~mL} / \mathrm{kg}$ $L M /$ minute is now considered a better indicator than the previous peak $\mathrm{VO}_{2}$ max cutoff of $14 \mathrm{~mL} / \mathrm{kg} /$ minute. $^{44}$
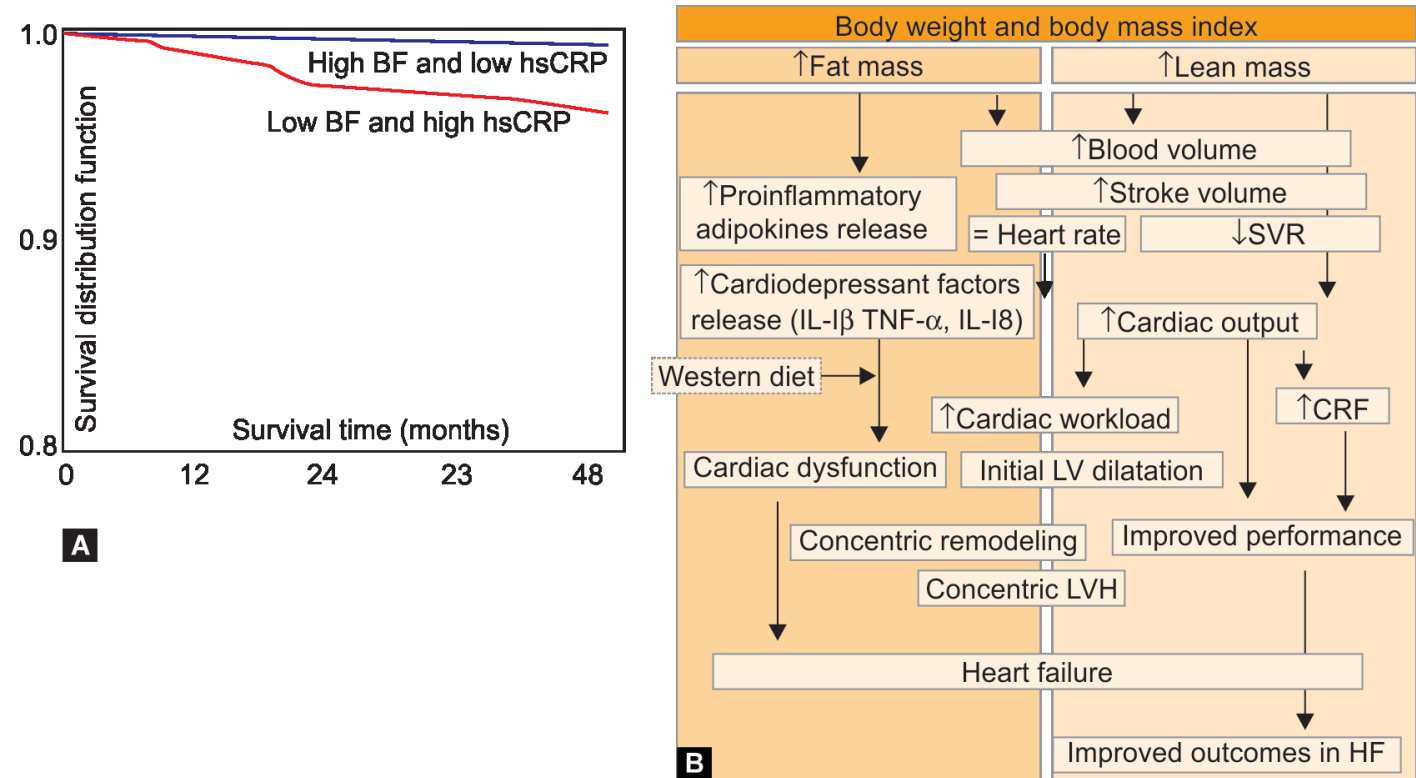

Figs 4A and B: (A) Survival estimates (Kaplan-Meier) by body fat (BF) and high-sensitivity C-reactive protein (hsCRP) strata: low hsCRP $=$ CRP $<3$ $\mathrm{mg} / \mathrm{L}$; high hsCRP $=\mathrm{CRP} \geq 3 \mathrm{mg} / \mathrm{L}$; low $\mathrm{BF}=\mathrm{BF}<25 \%$; high $\mathrm{BF} \geq 25 \%$. Reproduced from The impact of inflammation on the obesity paradox in coronary heart disease. ${ }^{43} \mathrm{CRP}, \mathrm{C}$-reactive protein; (B) Proposed mechanisms driving obesity to heart failure (HF) and the obesity paradox once $\mathrm{HF}$ is diagnosed. The dark blue arrows indicate the potentially detrimental effects of body composition components (fat mass and lean mass) on cardiac function and eventually HF development. The light blue arrows indicate the potential mechanisms by which body composition improves cardiorespiratory fitness. Reprinted from Obesity and heart failure: focus on the obesity paradox. ${ }^{12}$ SVR, systemic vascular resistance; $\mathrm{CRF}$, cardiorespiratory fitness; LVH, left ventricular hypertrophy ${ }^{10}$ 
Recently, the American Heart Association has stressed the significance of measuring $\mathrm{CRF}^{45}$ Even after adjustment for other risk factors like $\mathrm{BMI}$ or visceral fat, improved CRF independently predicts a better event profile for CVD patients. From this stems, the novel concept that rather than BMI, the target for improving outcomes in CVD patients should be CRF.

Since a cardiopulmonary exercise test may not always be feasible, hence CRF can be estimated from peak exercise at the time of a treadmill test (or cycle ergometer test). ${ }^{45}$ Both isotonic and isometric exercise training are utilized to improve CRF for cardiac rehabilitation. ${ }^{46}$ In obese patients with heart failure and preserved ejection fraction (HFpEF), aerobic exercise done under supervision for 1-hour at least thrice in a week for 20 weeks improves CRF by $1.2 \mathrm{~mL} / \mathrm{kg} /$ minute. The benefit can be further improved to $2.5 \mathrm{~mL} /$ $\mathrm{kg} /$ minute through diet modifications. ${ }^{4}$

Besides improved CRF, other explanations cited for the occurrence of obesity paradox include: ${ }^{47}$

- Comorbid conditions like malignancy, multiorgan dysfunction, etc., and advanced age are more common in lean patients.

- In obese patients, CVD is usually diagnosed earlier.

- Raised serum lipoproteins in obesity may neutralize bacterial endotoxins.

- In critically ill, fat depots may serve to maintain energy balance, and therefore prevent wasting.

\section{Investigations of CVS in Obese}

Due to the huge impact on the overall CVD profile, obesity even in an asymptomatic patient warrants evaluation of cardiovascular health. According to a meta-analysis, left ventricular hypertrophy (LVH) is four times more likely to develop in obese individuals. Eccentric hypertrophy is more common than the concentric subtype. Also, more than half of obese patients have diastolic dysfunction and this shows a close correlation with abdominal circumference. ${ }^{48}$ Left atrial volume enlargement is also more common in obese. Thus screening tests are warranted to detect the cardiac complications related to obesity at an early stage.

Routine echocardiography derived indices are not a very sensitive tool to detect early deterioration in systolic and diastolic properties of the myocardium. Among emerging noninvasive modalities, "integrated backscatter" assessed by color Doppler imaging is a novel method to assess the state of compliance of the myocardium, its inotropic properties, and associated interstitial fibrotic changes in very early stages. ${ }^{49}$

\section{Current Management Options for Obesity}

\section{Lifestyle and Dietary Recommendations}

Although the excess visceral adiposity and ectopic fat have a genetic basis, diet clearly plays a pivotal role. The weight that is lost in the initial period determines the long-term success of such lifestyle measures. The recommendation is to lose $5-10 \%$ weight in the first 6 months. ${ }^{50}$ The recommendations from the International Chair on Cardiometabolic Risk are summarized in Figure $5 .{ }^{9}$

\section{Pharmacological Intervention}

Patients with $\mathrm{BMI} \geq 30 \mathrm{~kg} / \mathrm{m}^{2}$ (or $\geq 27 \mathrm{~kg} / \mathrm{m}^{2}$ for those with one or more obesity-related complications) are candidates for drug therapy to lose weight. ${ }^{9}$ Pharmacotherapy options currently approved in the United States and Europe include:

- Oral phentermine (15-30 mg) which acts as a sympathomimetic.

- Oral orlistat (120 mg thrice daily preceding meals) which is an inhibitor of pancreatic lipase.

- Oral lorcaserin (10 mg twice daily) acts as a selective agonist for the $5-\mathrm{HT}_{2 \mathrm{C}}$ serotonin receptor.

- Oral phentermine/topiramate $(7.5 \mathrm{mg} / 46 \mathrm{mg}$ or $15 \mathrm{mg} / 92$ $\mathrm{mg}$ ) - which has a pleiotropic action profile including facilitating sympathetic activity, antagonizing glutamate, modulation of GABA receptors, and inhibiting carbonic anhydrase.

- Naltrexone, which acts by opioid receptor antagonism and is used in fixed-dose combination with bupropion-a noradrenaline and dopamine reuptake inhibitor ( $32 \mathrm{mg} / 360 \mathrm{mg}$ orally).

- Injectable liraglutide (given as $3.0 \mathrm{mg}$ dose) acts by facilitating GLP-1 receptor function and is useful for promoting weight loss. ${ }^{51}$

No of these drugs have yet demonstrated improved cardiovascular outcomes or efficacy in reducing visceral adipose tissue or ectopic fat. ${ }^{51}$ Recently, trials of diabetes drugs empagliflozin and semaglutide (that have an impact on energy

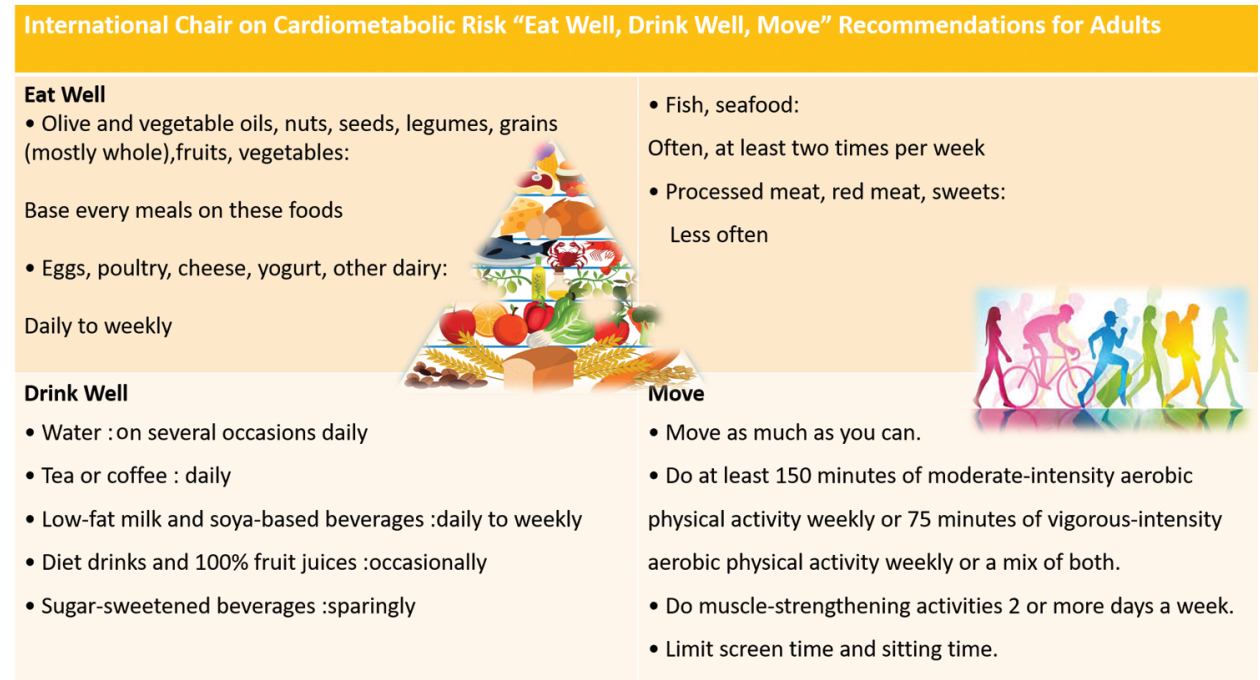

Fig. 5: Lifestyle management recommendations 
Table 1: Comparison of various bariatric surgery techniques

Restrictive procedure
Adjustable gastric banding Sleeve gastrectomy

T1DM, type 1 diabetes mellitus

balance) have shown, for the first time, a significant reduction in adverse cardiovascular outcomes. ${ }^{9}$

\section{Bariatric Surgery}

There are multiple guidelines suggesting criteria to identify patients who are likely to benefit from bariatric surgery. Guidelines from The American Diabetes Association, International Diabetes Federation, etc., consider weight-loss surgery as the sole modality that provides stable weight loss and ascertains improved prognosis. ${ }^{52,53}$ Bariatric surgery is indicated for patients having BMI above $40 \mathrm{~kg} / \mathrm{m}^{2}$ (or 35 $\mathrm{kg} / \mathrm{m}^{2}$ if associated OSA, diabetes, hypertension, etc., are present) when other treatment options have been exhausted. ${ }^{9}$

Bariatric surgeries are of two types restrictive or hybrid. Hybrid surgery combines restrictive and malabsorptive mechanical re-routing of the gastrointestinal tract. The frequency of complications and death-rate vary with the type of surgical modality, the amount of weight lost as well as its durability, and how promptly comorbid conditions are managed (summarized in Table 1). ${ }^{9}$ Hybrid procedures are best for weight loss and long-term outcomes. The 30-day complication rate post-surgery is below $10 \%$ (lower with restrictive surgeries) and the death rate is in the range of $0.1-1.2 \%$. Bariatric surgeries have been shown to improve cardiac geometry as well as the diastolic and systolic function of both ventricles. ${ }^{54}$

\section{SUMmARY}

Various CVDs are strongly influenced by excess bodyweight. The concept of adiposopathy underlies the common pathogenic mechanism related to these entities. Insights into the underlying mechanisms have unveiled that increased LM drives the better outcomes observed with the obesity paradox. An effective strategy should not only target weight loss but strive to improve the LM through exercise and dietary changes. Physicians should focus on improving CRF (and thus LM) for better clinical outcomes. We must recognize that the epidemic proportions reached by obesity are a reflection of societal conditions that extend beyond the traditional medical model. As key stakeholders, physicians can advocate for environments that promote human health rather than disease.

\section{References}

1. Poirier P, Giles TD, Bray GA, et al. Obesity and cardiovascular disease: pathophysiology, evaluation, and effect of weight loss [internet]. Arteriosclerosis, Thrombosis, and Vascular Biology, vol. 26. Arterioscler Thromb Vasc Biol; 2006. pp. 968-976. Available from: https://pubmed.ncbi.nlm.nih.gov/16627822/.

2. WHO, | Obesity: preventing and managing the global epidemic [Internet]. [cited 2020 Sep 26]. Available from: https://www.who.int/ nutrition/publications/obesity/WHO_TRS_894/en/.

3. Lavie CJ, Arena R, Alpert MA, et al. Management of cardiovascular diseases in patients with obesity [internet]. Nat Rev Cardiol, Nature Publishing Group 2018;15(1):45-56. DOI: 10.1038/nrcardio.2017.108. Available from: https://pubmed.ncbi.nlm.nih.gov/28748957/.

4. Carbone S, Canada JM, Billingsley HE, et al. Obesity paradox in cardiovascular disease: where do we stand? [internet]. Vasc Health Risk Manag, vol. 15. Dove Medical Press Ltd.; 2019. pp. 89-100. DOI: 10.2147/VHRM.S168946. Available from: /pmc/articles/ PMC6503652/?report=abstract.

5. GLOBAL STATUS REPORT on noncommunicable diseases 2014 "Attaining the nine global noncommunicable diseases targets; a shared responsibility.".

6. Ahirwar R, Mondal PR. Prevalence of obesity in India: a systematic review. Diabetes Metab Syndr, vol. 13. Elsevier Ltd; 2019. pp. 318-321.

7. ICMR guidelines for management of type 2 diabetes 2018 Indian Council of Medical Research, Ansari Nagar, New Delhi-110 029 ICMR Guidelines for Management of Type 2 Diabetes 2018 ICMR guidelines for management of type 2 diabetes 2018.

8. Hamer M, Stamatakis E. Metabolically healthy obesity and risk of allcause and cardiovascular disease mortality. J Clin Endocrinol Metab 
[Internet] 2012;97(7):2482-2488. DOI: 10.1210/jc.2011-3475. Available from: /pmc/articles/PMC3387408/?report=abstract.

9. Despres J-P, Larose E, Poirier P. Braunwald's Heart Disease Zipes DP, Libby P, Bonow RO, et al., ed. 11th ed., Elsevier Ltd; 2019. pp. 998-1004.

10. Wing RR, Bolin P, Brancati FL, et al. Cardiovascular effects of intensive lifestyle intervention in type 2 diabetes. N Engl J Med [Internet] 2013;369(2):145-154. DOI: 10.1056/NEJMoa1212914. Available from: https://pubmed.ncbi.nlm.nih.gov/23796131/.

11. Després JP. Body fat distribution and risk of cardiovascular disease: an update. Circulation [Internet] 2012;126(10):1301-1313. DOI: 10.1161/ CIRCULATIONAHA.111.067264. Available from: https://pubmed.ncbi. nlm.nih.gov/22949540/.

12. Carbone S, Lavie CJ, Arena R. Obesity and heart failure: focus on the obesity paradox [internet]. Mayo Clinic Proceedings, vol. 92. Elsevier Ltd; 2017. pp. 266-279. Available from: https://pubmed.ncbi.nlm.nih. gov/28109619/.

13. Segerjc, Mccarthyw HE, Bn S, et al., American Society of Bariatric Physicians Obesity Algorithm:, Adultadiposity. American Society of Bariatric Physicians (ASBP) ASBP Obesity Algorithm: Adult Adiposity Evaluation and Treatment 2013 Copyright $\odot 2013$ ASBP:Maynotbere producedoralteredinanyformwithoutwrittenpermissionfromASBP Citation.

14. Bays H. Adiposopathy, "sick fat," Ockham's razor, and resolution of the obesity paradox. Curr Atheroscler Rep [Internet] 2014;16(5):409. DOI: 10.1007/s11883-014-0409-1. Available from: https://pubmed. ncbi.nlm.nih.gov/24659222/.

15. Vassallo J. Pathogenesis of obesity the physiological basis of obesity [internet]. Malta Coll Pharm Pract 2007;12:19-22. Available from: https://www.um.edu.mt/library/oar/handle/123456789/13679.

16. Zhang Y, Liu J, Yao J, et al. Obesity: pathophysiology and intervention [internet]. Nutrients, MDPI AG 2014;6(11):5153-5183. DOI: 10.3390/nu6115153. Available from: https://pubmed.ncbi.nlm. nih.gov/25412152/.

17. Yudkin JS, Eringa E, Stehouwer CDA. "Vasocrine" signalling from perivascular fat: a mechanism linking insulin resistance to vascular disease [internet]. Lancet, vol. 365. Elsevier Limited; 2005. pp. 18171820. Available from: https://pubmed.ncbi.nlm.nih.gov/15910955/.

18. Schäffler A, Schölmerich J. Innate immunity and adipose tissue biology [internet]. Trends Immunol 2010;31(6):228-235. DOI: 10.1016/j.it.2010.03.001. Available from: https://pubmed.ncbi.nlm. nih.gov/20434953/.

19. Malavazos AE, Di Leo G, Secchi F, et al. Relation of echocardiographic epicardial fat thickness and myocardial fat. Am J Cardiol [Internet] 2010;105(12):1831-1835. DOI: 10.1016/j.amjcard.2010.01.368. Available from: https://pubmed.ncbi.nlm.nih.gov/20538139/.

20. Rosito GA, Massaro JM, Hoffmann U, et al. Pericardial fat, visceral abdominal fat, cardiovascular disease risk factors, and vascular calcification in a community-based sample the framingham heart study. Circulation [Internet] 2008;117(5):605-613. DOI: 10.1161/ CIRCULATIONAHA.107.743062. Available from: https://pubmed.ncbi. nlm.nih.gov/18212276/.

21. Ding J, Kritchevsky SB, Hsu FC, et al. Association between nonsubcutaneous adiposity and calcified coronary plaque: a substudy of the multi-ethnic study of atherosclerosis. Am J Clin Nutr [Internet] 2008;88(3):645-650. DOI: 10.1093/ajcn/88.3.645. Available from: https://pubmed.ncbi.nlm.nih.gov/18779279/.

22. Wong CX, Abed HS, Molaee $P$, et al. Pericardial fat is associated with atrial fibrillation severity and ablation outcome. J Am Coll Cardiol [Internet] 2011;57(17):1745-1751. DOI: 10.1016/j.jacc.2010.11.045. Available from: https://pubmed.ncbi.nlm.nih.gov/21511110/.

23. Shoelson $\mathrm{SE}$, Herrero L, Naaz A. Obesity, inflammation, and insulin resistance. Gastroenterology [Internet] 2007;132(6):2169-2180. DOI: 10.1053/j.gastro.2007.03.059. Available from: https://pubmed.ncbi. nlm.nih.gov/17498510/.

24. Ridker PM. C-reactive protein and the prediction of cardiovascular events among those at intermediate risk. Moving an inflammatory hypothesis toward consensus. J Am Coll Cardiol, vol. 49 Elsevier 2007(21):pp. 2129-2138. DOI: 10.1016/j.jacc.2007.02.052.
25. Din-Dzietham R, Liu Y, Bielo MV, et al. High blood pressure trends in children and adolescents in national surveys, 1963 to 2002. Circulation [Internet] 2007;116(13):1488-1496. Available from: https://www. ahajournals.org/doi/10.1161/CIRCULATIONAHA.106.683243.

26. Jamil G, Jamil M, Alkhazraji $H$, et al. Risk factor assessment of young patients with acute myocardial infarction. Am J Cardiovasc Dis [Internet] 2013;3(3):170-174. Available from: http://www.ncbi.nIm. nih.gov/pubmed/23991352.

27. Lavie CJ, Milani RV, Ventura HO. Obesity and cardiovascular disease. Risk factor, paradox, and impact of weight loss [internet]. J Am Coll Cardiol 2009;53(21):1925-1932. DOI: 10.1016/j.jacc.2008.12.068. Available from: https://pubmed.ncbi.nlm.nih.gov/19460605/.

28. Kenchaiah S, Evans JC, Levy D, et al. Obesity and the risk of heart failure. N Engl J Med [Internet] 2002;347(5):305-313. Available from: http://www.nejm.org/doi/abs/10.1056/NEJMoa020245.

29. Alpert MA, Terry BE, Mulekar M, et al. Cardiac morphology and left ventricular function in normotensive morbidly obese patients with and without congestive heart failure, and effect of weight loss. Am J Cardiol [Internet] 1997;80(6):736-740. DOI: 10.1016/S00029149(97)00505-5. Available from: https://pubmed.ncbi.nlm.nih. gov/9315579/.

30. Alpert MA, Omran J, Bostick BP. Effects of obesity on cardiovascular hemodynamics, cardiac morphology, and ventricular function [internet]. Curr Obes Rep 2016;5(4):424-434. DOI: 10.1007/s13679016-0235-6. Available from: https://pubmed.ncbi.nlm.nih.gov/ 27744513/.

31. Ebong IA, Goff DC, Rodriguez $C J$, et al. Mechanisms of heart failure in obesity [internet]. Obesity Research and Clinical Practice, vol. 8. Elsevier Ltd; 2014. pp. e540-e548. Available from: https://pubmed. ncbi.nlm.nih.gov/25434909/.

32. Olivier A, Pitt B, Girerd N, et al. Effect of eplerenone in patients with heart failure and reduced ejection fraction: potential effect modification by abdominal obesity. Insight from the EMPHASIS-HF trial. Eur J Heart Fail [Internet] 2017;19(9):1186-1197. DOI: 10.1002/ejhf.792. Available from: https://pubmed.ncbi.nlm.nih. gov/28303624/.

33. Torre-Amione G, Kapadia S, Benedict C, et al. Proinflammatory cytokine levels in patients with depressed left ventricular ejection fraction: a report from the studies of left ventricular dysfunction (SOLVD). J Am Coll Cardiol [Internet] 1996;27(5):1201-1206. DOI: 10.1016/0735-1097(95)00589-7. Available from: https://pubmed.ncbi. nlm.nih.gov/8609343/.

34. Hubert HB, Feinleib M, McNamara PM, et al. Obesity as an independent risk factor for cardiovascular disease: a 26-year follow-up of participants in the Framingham heart study. Circulation [Internet] 1983;67(5):968-977. Available from: https://www.ahajournals.org/ doi/10.1161/01.CIR.67.5.968.

35. Wang TJ, Parise H, Levy D, et al. Obesity and the risk of new-onset atrial fibrillation. J Am Med Assoc [Internet] 2004;292(20):2471-2477. DOI: 10.1001/jama.292.20.2471. Available from: https://jamanetwork. $\mathrm{com} /$.

36. Csige I, Ujvárosy D, Szabó Z, et al. The impact of obesity on the cardiovascular system [internet]. Journal of Diabetes Research. Hindawi Limited, vol. 2018 2018. p. 3407306. Available from: https:// pubmed.ncbi.nlm.nih.gov/30525052/.

37. Magnani JW, Hylek EM, Apovian CM. Obesity begets atrial fibrillation: a contemporary summary. Circulation [Internet] 2013;128(4):401405. Available from: https://www.ahajournals.org/doi/10.1161/ CIRCULATIONAHA.113.001840.

38. Lalani AP, Kanna B, John J, et al. Abnormal signal-averaged electrocardiogram (SAECG) in obesity. Obes Res [Internet] 2000;8(1):20-28. Available from: http://doi.wiley.com/10.1038/ oby.2000.4.

39. Kalantar-Zadeh K, Block G, Horwich T, et al. Reverse epidemiology of conventional cardiovascular risk factors in patients with chronic heart failure [internet]. J Am Coll Cardiol 2004;43(8):1439-1444. DOI: 10.1016/j.jacc.2003.11.039. Available from: https://pubmed.ncbi.nlm. nih.gov/15093881/. 
40. Oreopoulos A, Padwal R, Kalantar-Zadeh K, et al. Body mass index and mortality in heart failure: a meta-analysis. Am Heart J 2008;156(1):1322. DOI: 10.1016/j.ahj.2008.02.014.

41. Sharma A, Lavie CJ, Borer JS, et al. Meta-analysis of the relation of body mass index to all-cause and cardiovascular mortality and hospitalization in patients with chronic heart failure. Am J Cardiol [Internet] 2015;115(10):1428-1434. DOI: 10.1016/j.amjcard.2015.02.024. Available from: https://jhu.pure.elsevier.com/en/publications/ meta-analysis-of-the-relation-of-body-mass-index-to-all-causeand-3.

42. Horwich TB, Fonarow GC, Hamilton MA, et al. The relationship between obesity and mortality in patients with heart failure. J Am Coll Cardiol [Internet] 2001;38(3):789-795. DOI: 10.1016/S07351097(01)01448-6. Available from: https://pubmed.ncbi.nlm.nih. gov/11527635/.

43. De Schutter A, Kachur S, Lavie CJ, et al. The impact of inflammation on the obesity paradox in coronary heart disease. Int J Obes [Internet] 2016;40(11):1730-1735. DOI: 10.1038/ijo.2016.125. Available from: https://pubmed.ncbi.nlm.nih.gov/27453423/.

44. Clark AL, Fonarow GC, Horwich TB. Impact of cardiorespiratory fitness on the obesity paradox in patients with systolic heart failure. Am J Cardiol [Internet] 2015;115(2):209-213. DOI: 10.1016/j. amjcard.2014.10.023. Available from: https://linkinghub.elsevier.com/ retrieve/pii/S0002914914020116.

45. Ross R, Blair SN, Arena R, etal. Importance of assessing cardiorespiratory fitness in clinical practice: a case for fitness as a clinical vital sign: a scientific statement from the american heart association. Circulation [Internet] 2016;134(24):e653-e699. Available from: https://pubmed. ncbi.nlm.nih.gov/27881567/.

46. De Schutter A, Kachur S, Lavie CJ, et al. Cardiac rehabilitation fitness changes and subsequent survival. Eur Hear J - Qual Care Clin Outcomes [Internet] 2018;4(3):173-179. Available from: https:// pubmed.ncbi.nlm.nih.gov/29701805/.

47. Carbone S, Canada JM, Billingsley HE, et al. Obesity paradox in cardiovascular disease: where do we stand? [internet]. Vasc Health
Risk Manag, Dove Medical Press Ltd. 2019;15:89-100. DOI: 10.2147/ VHRM.S168946. Available from: https://pubmed.ncbi.nlm.nih. gov/31118651/

48. Cuspidi C, Rescaldani M, Sala C, et al. Left-ventricular hypertrophy and obesity: a systematic review and meta-analysis of echocardiographic studies [internet]. J Hypertens, Lippincott Williams and Wilkins 2014;32(1):16-25. DOI: 10.1097/HJH.0b013e328364fb58. Available from: https://pubmed.ncbi.nlm.nih.gov/24309485/.

49. Holland MR, Wallace KD, Miller JG. Potential relationships among myocardial stiffness, the measured level of myocardial backscatter ("image brightness"), and the magnitude of the systematic variation of backscatter (cyclic variation) over the heart cycle. J Am Soc Echocardiogr 2004;17(11):1131-1137. DOI: 10.1016/j.echo.2004. 06.004.

50. Gadde KM, Martin CK, Berthoud HR, et al. Obesity: pathophysiology and management [internet]. J Am Coll Cardiol, Elsevier USA 2018;71(1):69-84. DOI: 10.1016/j.jacc.2017.11.011. Available from: https://pubmed.ncbi.nlm.nih.gov/29301630/.

51. Bray GA, Frühbeck $G$, Ryan $D H$, et al. Management of obesity [internet]. The Lancet, Lancet Publishing Group 2016;387(10031):pp. 1947-1956. DOI: 10.1016/S0140-6736(16)00271-3. Available from: http://www.thelancet.com/article/S0140673616002713/ fulltext.

52. Association AD. 6. Obesity management for the treatment of type 2 diabetes. Diabetes Care [Internet] 2016;39(Suppl. 1):S47-S51. Available from: https://care.diabetesjournals.org/content/39/Supplement_1/ S47.

53. Dixon JB, Zimmet $P$, Alberti KG, et al. Bariatric surgery: an IDF statement for obese type 2 diabetes. Diabet Med [Internet] 2011;28(6):628-642. DOI: 10.1111/j.1464-5491.2011.03306.x. Available from:/pmc/articles/PMC3123702/?report=abstract.

54. Mingrone G, Panunzi S, De Gaetano A, et al. Bariatric surgery versus conventional medical therapy for type 2 diabetes. $N$ Engl J Med [Internet] 2012;366(17):1577-1585. DOI: 10.1056/NEJMoa1200111. Available from: http://www.nejm.org/doi/10.1056/NEJMoa1200111. 